\title{
Manajemen Pembelajaran Daring pada Masa Pandemi Covid-19 Di SD IT Lombok Tengah
}

\author{
Yusiana Apriani $^{1 *}$, Rusdiawan ${ }^{2}$, Asrin $^{3}$, Fahruddin $^{4}$, lalu Muhaimi ${ }^{5}$ \\ ${ }^{1}$ Magister Administrasi Pendidikan, Pascasarjana, Universitas Mataram, Indonesia \\ *aprianiyusiana@gmail.com
}

\begin{abstract}
Pademi covid-19 has disrupted the conventional learning process. So a solution is needed to answer these problems. Online learning is an alternative that can solve this problem. This study aims to describe the online implementation management by the head of the education unit, by teachers, by students, and by parents / guardians of students, identifying obstacles to online learning at SDIT Lombok in the middle of the 2020/2021 school year. This research uses a qualitative approach in the form of a case study. Data collection procedures used: (1) semi-structured interviews (Indept Interview), (2) participatory observation, (3) document study. Data analysis was carried out simultaneously with the data collection process. Data validity checking includes four techniques, namely credibility, transferability, dependability, and confirmability. The results of this study indicate that 1) the implementation of online learning at SD IT takes place online through the class whatsapp group platform; 2) the constraints that arise from online learning are the limitations of teachers in controlling student interest and motivation, limitations of parents in taking time and providing learning facilities and infrastructure, students prefer face-to-face learning.
\end{abstract}

Keywords: Management, Online, Covid-19 Pandemic, SD IT

Abstrak. Pademi covid-19 telah mengganggu proses pembelajaran secara konvensional. Maka diperlukan solusi untuk menjawab permasalahan tersebut. Pembelajaran secara daring adalah salah satu alternatif yang dapat mengatasi masalah tersebut. Penelitian ini bertujuan untuk mendeskripsikan manajemen pelaksanaan daring oleh kepala satuan pendidikan, oleh guru, oleh siswa, dan oleh orang tua/ wali siswa, mengidentifikasi kendala pembelajaran daring di SDIT Lombok tengah tahun ajaran 2020/2021. Penelitian ini menggunakan pendekatan kualitatif dalam bentuk studi kasus. Prosedur pengumpulan data menggunakan : (1) wawancara semi terstruktur (Wawancara Indept), (2) observasi partisipatif, (3) studi dokumen. Analisis data dilakukan bersamaan dengan proses pengumpulan data. Pemeriksanaan validitas data mencakup empat teknik, yaitu kredibilitas, transferabilitas, dependabilitas, dan konfirmabilitas. Hasil penelitian ini menunjukan bahwa 1) pelaksanaan pembelajaran daring di SDIT berlansgung secara daring melalui platform grup whatsapp kelas; 2) kendala yang muncul dari pembelajaran daring adalah keterbatasan guru mengontrol minat, dan motifasi belajar siswa, keterbatasan orang tua dalam dalam meluangkan waktu dan menyediakan sarana dan prasarana belajar, siswa lebih menyukai pembelajaran tatap muka.

Kata Kunci: Manajemen, Daring, Pandemi Covid-19, SD IT.

\section{PENDAHULUAN}

Pandemi Covid-19 menjadi persoalan multidimensi yang dihadapi dunia, hal tersebut juga dirasakan dampaknya dalam sektor pendidikan yang menyebabkan penurunan kualitas belajar pada siswa (Shahid, et al., 2020; Almaiah, et al., 2020; Garcia-Penalvo, et al., 2021). Covid-19 ini juga memberikan dampak serius pada sektor pendidikan di Indonesia tidak terkecuali Propinsi NTB khususnya di Kota Mataram. Sejumlah pemerintah daerah pun sudah meliburkan sekolah untuk mengantisipasi penyebaran COVID-19. Sebagian solusinya, pembelajaran di sekolah diganti dengan pembelajaran dalam jaringan (daring), atau akrab disebut online (Ramdani, et al., 2020). Masa darurat pandemi ini mengharuskan sistem pembelajaran diganti dengan pembelajaran daring agar proses pembelajaran tetap berlangsung (Sintema, 2020; Repanta, et al., 2020). Hal ini jelas mengubah pola pembelajaran yang mengharuskan guru dan 
pengembang pendidikan untuk menyediakan bahan pembelajaran dan mengajar siswa secara langsung melalui alat digital jarak jauh dengan memanfaatkan teknologi (Cheung, et al., 2014; Usak et al, 2020).

Pembelajaran daring mengundang pro dan kontra di masyarakat pada sektor pendidikan karena ketidaksiapan sumber daya, sarana dan anggaran (Z.R \& Saugi, 2018). Beberapa masalaah yang muncul dari penerapan pembelajaran jarak jauh ini muncul dari siswa, guru dan orang tua siswa. keluhan yang muncul berupa keterbatasan jaringan, keterbatasan kuota, keterbatasan waktu dan keterbatasan bakat dalam mengaplikasikan program yang berbasis internet.

SD IT Lombok Tengah satu satunya sekolah dari enam puluh dua sekolah dasar negeri dan swasta di kecamatan Jonggat ditunjuk oleh UPT sebagai calon sekolah percontohan tatanan baru. Hal tersebut karena kondisi sekolah dinilai layak sebagai sekolah percontohan. Segi kelayakannya berupa sarana dan prasarana yang memadai, tenaga pendidik yang cakap teknologi, kerja sama orang tua yang aktif dan kesiapan guru untuk melakukan kunjungan belajar kepada siswa yang terkendala akses jaringan maupun sarana.

Tenaga pendidik di SDIT GMC dipersiapakan secara matang untuk mengahadapi dan melaksanakan pembelajaran berbasis Information Technology (IT) seperti penggunaan media computer dan media android sebagai sumber belajar tambahan sebelum wabah Covid-19 menyerang dunia pendidikan. Hal tersebut menjadi bekal awal bagi pendidik untuk melaksanakan pembelajaran jarak jauh baik daring maupun luring dengan maksimal.

Pemanfaatan media computer dan android sebagai media pembelajaran merupakan salah satu dari indikator yang harus dimiliki oleh guru dan siswa pada era 4.0 (Gunawan et al., 2021). Guru di masa kini abad ke-21 harus kreatif dan membekali diri untuk mengajar di era teknologi, guru tidak bisa lagi menahan diri pada pengembangan diri dalam aspek yang dibutuhkan untuk generasi sekarang dan generasi yang akan datang dan teknik inovatif baru sangat penting untuk dikembangkan dalam diri seseorang siswa (Ma'ruf, et al., 2019).
Selain kecakapan tenaga pendidik dalam pengoprasian IT, subsidi kuota interenet dari yayasan menunjang keberlangsungan pembelajaran jarak jauh dengan optimal. Para guru disubsidi dengan kuota intenet sehingga para guru dapat melaksanakan daring dari rumah guru tersebut kapanpun tanpa harus berada di sekolah untuk menggunakan jaringan wifi.

Penerapan pembelajaran Daring dimulai sejak awal Juni dengan menggunkaan media elektronik dan jaringan internet sebagai media belajar anak dan guru. Sementara bagi siswa yang tidak memiliki media elektronikdan keterbatasan jaringan sekolah melakukan home visit (kunjungan rumah). Penelitian ini bertujuan untuk mendeskripsikan pelaksanaan dan faktor penghambat apa saja yang mempengaruhi pembelajaran daring diSD IT Lombok Tengah.

\section{METODE}

Penelitian ini menggunkaan pendekatan kualitatif dengan metode studi kasus. Penelitian kualitatif mengunakan metode pengumpulan data dengan teknik wawancara, observasi dan dokumentasi (Mohajan, 2018). Penelitian ini dilaksakanakn di SD IT Lombok Tengah.

Sumber data dalam penelitian ini dikelompokan menjadi dua yaitu, sumber data primer dan sumber data sekunder. Sumber data primer adalah pernyataan dan tindakan ornag yang diamati atau diwawancara yang direkam melalui catatn tertulis dan pengambilan foto. Sedangkan data sekunder adalah data yang berupa dokumen, foto atau catatan lain yang menunjang informasi dari informan (Moleong, 2014). Data primer diperoleh dari informan yaitu kepala sekolah, wakil kepala sekolah bagian humas, wakil kepala sekolah bagin kepeserta didikan, pegawai tata usaha, guru kelas, orag tua peserta didik, dan satpam. Data sekunder bersumber dari dokumen resmi yang ada dalam bentuk catataan, arsip, gambar, dan bahan lain yang berkaitan dengan penelitian ini. Penelitian ini menngunakan pengumpulan data dengan teknik wawancara semi terstruktur, observasi partisipatif, dan analisis dokumen (Ulfatin, 2017).

Miles dan Huberman (1992) menyatakan bahwa analilis pengumpulan data dapat 
dilakukan selama dan sesudah selesai dilapangan secara terus menerus sampai tuntas. Penelitian ini menngunkan teknik analisis data sesudah di lapangan dengan teknik analisis data interaktif sehingga data yang diperoleh jenuh, artinya tidak ada perbeaan infoemasi dari informan ynag satu dengan yang lian dan dengan teknik satu dengan teknik yang lain. Adapun proses analissi data yang dilakukan menliputi reduksi data, penyajian data dan penarikan kesimpulan. Adapun untuk menguji keabsahan data pada penelitian ini menggunakan empat langkah uji kredibiltas data yaitu uji kredibilitas, mencakup triangulasi, perpanjanan pengamatan, diskusi dengan teman sejawat dan member chek; uji teransferabilitas, uji dependabilitas dan uji konfirmabilitas.

\section{HASIL DAN PEMBAHASAN}

Selama masa pandemi Covid-19 pembelajaran di rumah atau online menjadi solusi melanjutkan sisa semester. Pembelajaran online didefinisikan sebagai pengalaman transfer pengetahuan menggunakan video, audio, gambar, komunikasi teks ke perangkat lunak (Basilaia \& Kvavadze, 2020) dan dengan dukungan jaringan internet (Chen, et al., 2020). Ini merupakan modifikasi transfer pengetahuan melalui forum website (Basilaia \& Kvavadze, 2020) dan tren teknologi digital sebagai ciri khas dari revolusi industry 4.0 untuk menunjang pembelajaran selama masa pandemi Covid-19. Integrasi teknologi dan ragam inovasi ciri dari pembelajaran online (Banggur, 2020). Selain itu, yang terpenting adalah kesiapan pendidik dan siswa untuk berintereaksi secara online. Penelitian di SD IT memanfaatkan media Learning Management Systems (LMS), Via Group Whatshap (WAG), google clashroom, google meet dan Moodle untuk pembelajaran pada masa pandemi Covid-19.

Salah satu syarat penggunaan LMS dalam proses pembelajaran, pendidik dan siswa harus terkoneksi dengan jaringan internet yang memadai. LMS memiliki beberapa fitur yang mendukung proses pembelajaran online, misalnya forum diskusi, kurikulum sumber belajar, kuis, tugas, jenis informasi akademik, dan pengelolaan data mahasiswa. Terdapat beberapa jenis LMS yang dapat dimanfaatkan dalam proses pembelajaran diantaranya adalah Schoology, Learnboos, Edmodo, Moodle dan lain-lain.

Untuk melaksanakan pembelajaran secara online, diperlukan suatu aplikasi yaitu learning management system (LMS). LMS merupakan suatu aplikasi atau software yang digunakan untuk mengelola pembelajaran online yang meliputi beberapa aspek yaitu materi, penempatan, pengelolaan, dan penilaian (Mahnegar, 2012).

Di beberapa daerah proses pembelajaran dari rumah telah berlangsung diperpanjang dengan mempertimbangkan situasi dimasingmasing daerah. Dari sisi sumber daya manusia, pendidik maupun peserta didik ada yang memang sudah siap. Tetapi banyak pula yang terpaksa harus siap menghadapi pembelajaran yang biasanya dilaksanakan secara tatap muka berubah menjadi sistem belajar jarak jauh secara daring. Bagi sekolah yang telah terbiasa menggunakan perangkat teknologi dalam kegiatan belajar mengajar tentu tidak banyak menghadapi kendala, Tetapi tidak demikian bagi sekolah yang belum pernah melaksanakan PJJ sebelumnya, terutama di daerah sisi peranti maupun jaringan. Lembaga pendidikan misalnya

SD IT menggunakan e-learning sebagai sarana pendidikan di mana sudah siap dari sisi sumberdaya manusia, memiliki kurikulum yang matang, serta dilengkapi fasilitas untuk mengakses sumber belajar dan sarana komunikasi yang efektif antara mahasiswa dan tutor. Namun, masih banyak lembaga pendidikan terutama yang berada di daerah tertinggal, jauh dari siap akibat berbagai keterbatasan. Sebagian besar proses PJJ saat ini masih memanfaatkan fasilitas grup Whatsapp dalam perangkat smart phone. Guru memberikan tugas kepada para peserta didik melalui grup Whatsapp, baik melalui grup orang tua siswa maupun grup kelas masing-masing. Waktu belajar sesuai dengan jadwal mata pelajaran harian. Materi belajar dipelajari secara mandiri kemudian dilanjutkan dengan mengerjakan tugas harian. Diskusi terkait materi yang dipelajari dilakukan melalui grup tersebut. Untuk mengadakan tatap muka virtual dapat menggunakan aplikasi Google Classroom, 
Zoom, atau media lainnya. Dengan fitur ini, guru bisa memantau kehadiran dan keaktifan peserta didik.

Pelaksanaan Pembinaan dan pemantauan kepada guru dalam pembelajaran daring masa pandemi covid-19 di SD IT Lombok Tengah dilakukan dengan cara memfasilitasi guru dengan kuota internet dan pulsa yang di berikan dari yayasan dengan tujuan agar guru tetap bisa melayani peserta didik kapanpun dan dimanapun tanpa bergantung dengan jaringan wifi di sekolah. Selain itu, sekolah juga memfasilitasi guru dengan laptop sekolah bagi guru yang bermasalah dengan gawai. Sementara itu, kepala sekolah selalu memastikan guru melaksanakan pembelajaran bermakna tentang kecakapan hidup dan aktivitas fisik. SD IT GMC juga membentuk Tim siaga darurat untuk pencegahan penularan dan penanganan covid19. Waka humas ditunjuk sebagai ketua tim tersebut dan berkoordinasi dengan puskesmas setempat di bantu oleh guru guru-guru lain dan satpam untuk bertugas secara bergiliran menyemprotkan cairan disinfektan pada semua fasilitas sekolah, mengecek suhu tubuh, penertiban penggunaan masker, menjaga jarak setiap warga sekolah dan menyediakan alat dan bahan cuci tangan bagi guru dan warga sekolah yang hendak melakukan daring dari sekolah.

Dalam pelaksanaan pembelajaran daring, seringkali ditemukan kendala ataupun ketidaksesuaian dengan pembelajaran yang seharusnya, banyak yang mengira tanggung jawab pengajar dalam melaksanakan pembelajaran jarak jauh lebih ringan ketimbang dengan Pembelajaran tradisional (Semradova \& Hubackova, 2016). Saat ini sistem pendidikan menghadapat banyak masalah, dalam masa pandemi Covid-19 pembelajaran di Indonesia dialihkan menjadi Pendidikan jarak jauh, namun kurangnya peralatan, personel, sumber daya, dan keterbatasan teknologi pendidikan, serta keterampilan dan kualitas yang dimiliki pengajar belum mencukupi Yustiqvar, et al., 2019; Widodo, et al., 2020). Penggunaan media internet/e-learning memiliki kendala yang cukup besar, koneksi jaringan dan kesalahan teknis seperti server down and error menghambat keberhasilan pembelajaran (Nurmukhametov et al., 2015).
Dalam suatu wawancara sejumlah guru di sekolah mengakui bahwa pembelajaran daring ini kurang efektif apabila dibandingkan dengan pembelajaran tatap muka langsung, karena beberapa alasan, yaitu:

"Pertama, konten materi yang disampaikan secara daring belum tentu bisa dipahami semua peserta didik. Sebab konten materi ini disajikan dalam bentuk e-book yang disajikan per bab, materi berbentuk powerpoint, dan dalam bentuk video pembelajaran. Mungkin materi dapat dipahami, tetapi pemahaman peserta didik tidak komprehensif. Mereka memahami berdasarkan tafsiran atau sudut pandang mereka sendiri. Hal ini terbukti dari pengalaman di lapangan, banyak sesuai yang meminta penjelasan lebih lanjut terhadap materiyang disajikan secara daring melalui chatting whatshapp atau menelepon langsung kepada guru. Tampaknya, menurut hemat penulis dan berdasarkan pengalaman mengajar secara daring, sistem ini hanya efektif untuk member penugasan dan kuis. Artinya, ketika dalam suatu pertemuan, peserta didik diberikan tugas/kuis, mereka ada ketekunan untuk menelaah bahan ajar yang tersedia di aplikasi atau mencari dari sumber-sumber lain, sehingga ada "kegelisahan" jika tugas/kuis belum diselesaikan. Berbeda halnya apabila guru memposting materi yang tidak disertai penugasan, hanya diminta mempelajarinya, maka ceritanya akan lain;

"Kedua, keterbatasan guru dalam melakukan kontrol saat berlangsungnya pembelajaran daring. Hal ini antara lain disebabkan aplikasi yang digunakan tidak menyajikan menu forum diskusi untuk menjelaskan atau menanyakan materi. Kalaupun ada menu tersebut.

Peserta didik tidak memanfaatkannya dengan baik. Sebab lainnya, peserta didik pada saat awal pembelajaran mengisi daftar hadir, setelahnya tidak aktif lagi sampai selesai waktu pembelajaran, pergi untuk melakukan aktivitas lain di luar pembelajaran. Namun, tidak boleh di-nafi-kan sama sekali, banyak peserta didik benar-benar aktif hingga pembelajaran selasai, dan adajuga yang aktif tetapi tidak full sampai pembelajaran berakhir. 
Pembelajaran daring dapat berjalan sesuai kondisi yang dialami dengan berbagai permasalahan yang muncul baik yang sederhana maupun kompleks. Setiap permasalahan yang dihadapi dapat diselesaikan dengan menghadirkan beragam solusi dari para guru sehingga pembelajaran di masa pandemi Covid19 tetap berlangsung, yang penting anak tetap belajar dan terus belajar meskipun belajar dari rumah. Sebab pelaksanaan belajar dari rumah ini tidak mengejar ketuntasan kurikulum, tetapi menekankan pada kompetensi literasi dan numerasi (Asmuni, 2020). Dalam penerapan pembelajaran daring, guru menggunakan berbagai perangkat teknologi di bidang pendidikan dan mampu memilih berbagai aplikasi yang sesuai kebutuhan dan karakteristik mata pelajaran, peserta didik, dan situasi lingkungan yang dihadapi, sehingga dapat membantu untuk menyampaikan materi pembelajaran (transfer of knowledge) kepada peserta didik. Meskipun diakui bahwa dalam praktik pembelajaran daring ini guru lebih dominan dalam pemberian tugas, bukan penjelasan materi (Nurhayati, 2020). Namun hakekatnya, peran guru itu tidak bisa tergantikan dengan teknologi bagaimanapun canggihnya.

Penggunaan teknologi di bidang pendidikan hanya mampu membantu guru dalam transfer of knowledge, bukan pada pembentukan karakter peserta didik. Sejalan dengan apa yang ungkapkan oleh Hadisaputra, et al (2019) bahwa teknologi tidak bisa menggantikan posisi guru. Kalaupun akan ada robot, tetapi sekedar mengajar bukan mendidik. Tugas mendidik ini hanya bisa dilakukan seorang guru secara langsung. Ditegaskan pula bahwa revolusi industri 4.0 tidak akan mampu menggantikan peran guru sebagai tenaga pendidik.

Pada prinsipnya, menurut Gunawan, et al (2021) pembelajaran daring atau pembelajaran jarak jauh di masa pandemi Covid-19 dan masa kebiasaan baru memperhatikan hal-hal berikut, a) tidak membahayakan, sebagaimana guru di seluruh dunia yang mencoba untuk mengurangi kemungkinan kerugian dalam belajar, karena gangguan sekolah; b) tidak membebani peserta didik dengan tugas-tugas yang memberatkan; dan c) memberikan pengalaman belajar yang bermakna dengan menerapkan strategi dan metode pembelajaran yang sesuai dengan kondisi dan materi; dan fokus pada pendidikan kecakapan hidup, khusus pencegahan dan penanganan pan demi Covid 19, perilaku hidup bersih dan sehat dan gerakan masyarakat sehat. Sejalan pula apa yang dikemukakan Nadim Makarim, bahwa prinsip kebijakan pendidikan di masa pandemi covid-19 adalah mengutamakan kesehatan dan keselamatan peserta didik, pendidik, tenaga kependidikan, keluarga, dan masyarakat secara umum, serta mempertimbangkan tumbuh kembang peserta didik dan kondisi psiko sosial dalam upaya pemenuhan layanan pendidikan.

\section{KESIMPULAN}

Proses belajar dari rumah yang dilaksanakan saat ini belum dapat disebut sebagai kondisi belajaryang ideal, melainkan kondisi darurat yang harus dilaksanakan. Masih terdapat berbagai kendala sehingga semua pembelajaran dapat optimal. Pemerintah bekerja sama dengan berbagai sektor terkait melakukan berbagai upaya untuk dapat mengatasi hambatan yang terjadi dalam PJJ, baik dari sisi regulasi, peningkatan kesiapan pendidik, serta perluasan jaringan dan akses sumber belajar, agar dapat berjalan secara efektif. Namun demikian, upaya tersebut perlu terus ditingkatkan agar optimalisasi PJJ

tidak hanya untuk kondisi darurat seperti saat ini tetapi juga untuk dilaksanakan dalam situasi normal sesuai dengan kebutuhan belajar.

\section{SARAN}

Guru diharapkan tetap membangun kerja sama tim, taat protokol kesehatan, dan melaksanakan tugas mengajar yang lebih baik dengan mengacu pada 4 (empat) kompetensi yang melekat pada diri guru, yaitu kompetensi padagogik, kepribadian, profesional, dan sosial. Orang tua siswa, diharapkan koopertaif, kamunikatif dan aktif dalam pendampingan pembelajaran daring dan luring masa pandemic covid-19 baik dengan pihak sekolah maupun dengan anak sendiri. 


\section{DAFTAR PUSTAKA}

Almaiah, M. A., Al-Khasawneh, A., \& Althunibat, A. (2020). Exploring the critical challenges and factors influencing the E-learning system usage during COVID-19 pandemic. Education and Information Technologies, 25, 5261-5280.

Asmuni, A. (2020). Problematika Pembelajaran Daring di Masa Pandemi Covid-19 dan Solusi Pemecahannya. Jurnal Paedagogy, 7(4), 281-288.

Banggur, M. D. V. (2020). Blended Learning: Solusi Pembelajaran Di Era Revolusi Industri 4.0.

Basilaia, G., \& Kvavadze, D. (2020). Transition to online education in schools during a SARS-CoV-2 coronavirus (COVID-19) pandemic in Georgia. Pedagogical Research, 5(4), 1-9.

Chen, J., Qi, T., Liu, L., Ling, Y., Qian, Z., Li, T., \& Song, Z. (2020). Clinical progression of patients with COVID-19 in Shanghai, China. Journal of Infection.

Cheung, C. L., Looi, T., Lendvay, T. S., Drake, J. M., \& Farhat, W. A. (2014). Use of 3-dimensional printing technology and silicone modeling in surgical simulation: development and face validation in pediatric laparoscopic pyeloplasty. Journal of surgical education, 71(5), 762-767.

García-Peñalvo, F. J., Corell, A., Abella-García, V., \& Grande, M. (2020). Online assessment in higher education in the time of COVID-19. Education in the Knowledge Society, 21.

Gunawan, G., Jufri, A. W., Nisrina, N., AlIdrus, A., Ramdani, A., \& Harjono, A. (2021, February). Guided inquiry blended learning tools (GI-BL) for school magnetic matter in junior high school to improve students' scientific literacy. In Journal of Physics: Conference Series (Vol. 1747, No. 1, p. 012034). IOP Publishing.

Gunawan, G., Purwoko, A. A., Ramdani, A., \& Yustiqvar, M. (2021). Pembelajaran Menggunakan Learning Management
System Berbasis Moodle pada Masa Pandemi Covid-19. Indonesian Journal of Teacher Education, 2(1), 226-235.

Hadisaputra, S., Gunawan, G., \& Yustiqvar, M. (2019). Effects of Green Chemistry Based Interactive Multimedia on the Students' Learning Outcomesand Scientific Literacy. Journal of Advanced Research in Dynamical and Control Systems, 11(7), 664-674.

Ma'Ruf, M., Marisda, D. H., \& Handayani, Y. (2019, February). The basic physical program based on education model online assisted by alfa media to increase creative thinking skills. In Journal of Physics: Conference Series (Vol. 1157, No. 3, p. 032068). IOP Publishing.

Mahnegar, F. (2012). Learning management system. International Journal of Business and Social Science, 3(12).

Mohajan, H. K. (2018). Qualitative research methodology in social sciences and related subjects. Journal of Economic Development, Environment and People, 7(1), 23-48.

Moleong, L. J. (2015). Metode PenelitianKuelitatif. Bandung: Remaja Rosdakarya.

Nurhayati, E. (2020). Meningkatkan keaktifan siswa dalam pembelajaran daring melalui media game edukasi quiziz pada masa pencegahan penyebaran covid-19. Jurnal Paedagogy, 7(3), 145150.

Ramdani, A., Jufri, A. W., \& Jamaluddin, J. (2020). Pengembangan Media Pembelajaran Berbasis Android pada Masa Pandemi Covid-19 untuk Meningkatkan Literasi Sains Peserta Didik. Jurnal Kependidikan: Jurnal Hasil Penelitian dan Kajian Kepustakaan di Bidang Pendidikan, Pengajaran dan Pembelajaran, 6(3), 433-440.

Rapanta, C., Botturi, L., Goodyear, P., Guàrdia, L., \& Koole, M. (2020). Online university teaching during and after the Covid-19 crisis: Refocusing teacher presence and learning 
activity. Postdigital Science and Education, 2(3), 923-945.

Semradova, I., \& Hubackova, S. (2016). Teacher responsibility in distance education. Procedia-Social and Behavioral Sciences, 217, 544-550.

Shahid, Z., Kalayanamitra, R., McClafferty, B., Kepko, D., Ramgobin, D., Patel, R., ... \& Jain, R. (2020). COVID-19 and older adults: what we know. Journal of the American Geriatrics Society, 68(5), 926-929.

Sintema, E. J. (2020). Effect of COVID-19 on the performance of grade 12 students: Implications for STEM education. Eurasia Journal of Mathematics, Science and Technology Education, 16(7), em1851.

Usak, M., Masalimova, A. R., Cherdymova, E. I., \& Shaidullina, A. R. (2020). New playmaker in science education: COVID-19. Journal of Baltic Science Education, 19(2), 180-185.

Widodo, W., Sudibyo, E., Suryanti, S., Sari, D. A. P., Inzanah, I., \& Setiawan, B. (2020). The effectiveness of gadgetbased interactive multimedia in improving generation z's scientific literacy. Jurnal Pendidikan IPA Indonesia, 9(2), 248-256.

Yustiqvar, M., Hadisaputra, S., \& Gunawan, G. (2019). Analisis penguasaan konsep siswa yang belajar kimia menggunakan multimedia interaktif berbasis green chemistry. Jurnal Pijar Mipa, 14(3), 135-140.

ZR, H. N., \& Saugi, W. (2020). Pengaruh Kuliah Online Terhadap Minat Belajar Mahasiswa Pendidikan Agama Islam (PAI) Di IAIN Samarinda. El-Buhuth: Borneo Journal of Islamic Studies, 2(2), 121-131. 